\title{
Dois Estudos Sobre o Trabalho dos Petroleiros
}

\section{Leda Leal Ferreira}

Coordenadoria de Ergonomia - FUNDACENTRO

Rua Capote Valente, 710 - São Paulo - SP - 05409-002

Palavras chaves: petroleiros, análise do trabalho, atividade em situação de trabalho, trabalho perigoso, trabalho complexo, trabalho contínuo e trabalho coletivo.

Key words: petroleum workers, work analyses, activities in work situations, unsafe work, complex work, shift work and collective work.

\section{RESUMO}

O presente artigo traz um resumo de dois estudos realizados na área do petróleo, o primeiro feito em uma unidade de refino e o segundo abarcando o trabalho de operadores exercendo várias funçōes dentro de uma refinaria e de terminais marítimos de petróleo. Nos dois casos, o ponto central foi a análise da atividade dos trabalhadores, istoé, o que eles faziam e como o faziam para dar conta das exigências de produção que lhes eram atribuídas. No entanto, os métodos utilizados foram diferentes: no primeiro caso utilizou-se a Análise Ergonômica do Trabalho (AET) e no segundo, a Análise Coletiva do Trabalho (ACT). Além de apresentar os principais resultados destes estudos, a autora faz considerações sobre as diferenças entre os dois métodos e um apelo à comunidade científica para que se preocupe mais em estudar a atividade real dos trabalhadores e assim contribuir para um melhor conhecimento do que se passa no interior das unidades produtivas, evitando que sofrimentos humanos inúteis e até catástrofes industriais continuem a ocorrer.

\begin{abstract}
This paper describes two studies about petroleum industry. The first was developed in a refinery and the second focuses on the work of operators in various jobs within a refinery and maritime petroleum units. In both cases, the focal point was the analyses of activities, that is, what the workers do and how they do it in order to meet production demandas put on them. However, two different methods were applied in the studies. Ergonomics Work Analyses (EWA) was used on the first case and Collective Work Analyses (CWA), on the second. Besides showing the main results, the author compares the two methods. She also draws the scientific community attention to the importance of studding the workers actual activity in order to contribute to a better understanding of what is going on inside production units, avoiding useless human suffering, and the still ocurring undustrial disasters.
\end{abstract}




\section{PRODUÇÃO}

Nos últimos anos, realizei, com alguns colaboradores, dois estudos na área do petróleo; o primeiro, em 1990/91, em uma unidade de uma das refinarias de petróleo do Estado de São Paulo. O segundo, em 1993/94, feito em conjunto com um Sindicato de petroleiros teve como objeto o trabalho desenvolvido em vários setores e unidades da mesma refinaria e em dois terminais marítimos de petróleo, unidades da base deste Sindicato. Em ambos os casos, o ponto central do estudo foi a análise da atividade real dos trabalhadores, isto é, o que eles faziam e como o faziam para dar conta das exigências de produção que lhes eram atribuídas. No estudo de 1990, a análise da atividade estava inserida num método chamado de Análise Ergonômica do Trabalho (AET); no estudo de 1993, utilizou-se outro método- a Análise Coletiva do Trabalho (ACT).

Neste texto, o objetivo é apresentar um resumo destes dois estudos e fazer algumas considerações gerais sobre seus métodos e resultados.

\section{AET e ACT: Semelhanças e Diferenças}

A Análise Ergonômica do Trabalho (AET) foi elaborada há cerca de 25 anos por pesquisadores de um centro de ergonomia da França, o então Laboratoire de Physiologie du Travail et Ergonomie, do Conservatoire National des Arts et Métiers, CNAM, dirigido por A.Wisner. Suas origens, porém, podem ser encontradas na obra de A. Ombredane e J. M. Faverge, principalmente no seu livro A Análise do Trabalho. de 1955, que propunha uma mudança no estudo do trabalho: não mais estudar as tarefas descritas pela direção mas analisar, na prática, as atividades reais dos trabalhadores. Ao longo deste período, a AET foi aplicada em inúmeras situações práticas e vários de seus pontos foram aperfeiçoados. No entanto, suas etapas básicas continuam válidas. São elas (Wisner,1994): 1-análise da demanda; 2análise do ambiente técnico, econômico e social; 3-análise das atividades em situação de trabalho e restituição dos resultados,4-recomendações ergonômicas, e 5-validação da intervenção e eficiência das recomendações. Essencialmente, o que este método propõe é um caminho de raciocínios e ações que parta de uma problemática (a demanda) e chegue a uma solução (recomendações de mudança).Sua parte central é a análise das atividades em situação de trabalho, ou seja, a análise do que o trabalhador faz concretamente na sua situação de trabalho para responder às exigências de sua tarefa. Esta análise deve ser feita in loco pelo(s) ergonomista(s), através de uma série de técnicas que podem ir da observação livre a certos estudos em condições controladas, passando por toda uma série de avaliações $\mathrm{e}$, eventualmente, de mensurações de parâmetros.

Já a Análise Coletiva do Trabalho (ACT), se teve sua inspiração inicial na AET, dela se distancia na medida em que propõe que a análise seja feita pelos próprios trabalhadores que executam a atividade estudada. Na ACT, são trabalhadores, em grupo, que analisam seu próprio trabalho, auxiliados por ergonomistas. Através de perguntas 
concretas - o que você faz? onde você trabalha? com que você trabalha? que equipamentos utiliza? o que acontece quando você erra? quais regras você deve seguir? etc -os ergonomistas vão orientando a descrição dos trabalhadores. A experiência prática dos ergonomistas em matéria de análise ergonômica da atividade, a sua sensibilidade em situações de grupo e a empatia com os participantes são determinantes para a formulação de perguntas pertinentes e para o desenvolvimento das reuniões. Diferentemente do que ocorre na AET, na ACT o processo ocorre fora da situação de trabalho e o método só pode ser utilizado se os trabalhadores quiserem participar dele, voluntariamente (Ferreira,1993).

O quadro abaixo mostra algumas das diferenças e semelhanças entre os dois métodos.

\section{O Primeiro Estudo: AET e o Problema do Efetivo de Trabalhadores}

O primeiro estudo se deu nos quadros de um conflito entre operadores e direção da empresa, que havia diminuído o número de operadores por turno de uma determinada unidade de refino. Os operadores argumentavam que a diminuiçã̃o colocava em risco não só a segurança da unidade como até a da população vizinha, tendo em vista que, devido aos produtos perigosos que ela utilizava, um acidente grave poderia ter seus efeitos a quilômetros de distância. Não tendo sido possível se chegar a um consenso entre as duas partes, órgãos públicos foram acionados. $E$ foi neste contexto que o Ministério Público do

\begin{tabular}{|c|c|c|}
\hline & $\mathrm{AET}$ & $\mathrm{ACT}$ \\
\hline OQUESEANAISA? & $\begin{array}{l}\text { aatividadedos trabalhadaresem } \\
\text { siluraçäodetraballho }\end{array}$ & $\begin{array}{l}\text { aatividadedos trabalhadoresem } \\
\text { situraçäodetraballho }\end{array}$ \\
\hline QUEMANAISA? & $\begin{array}{l}\text { ergonomistas, ajudadospor } \\
\text { trabalhadres }\end{array}$ & $\begin{array}{l}\text { trabalhadares ajudadospar } \\
\text { engmonistas }\end{array}$ \\
\hline ONDESEANAIISA? & napúpriasituaçãodetrabalho & fradasituagãodetrabalho \\
\hline COMOSEANAISA? & 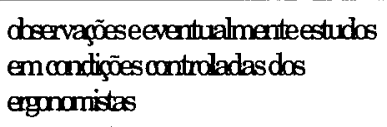 & $\begin{array}{l}\text { descricäooral daatividadepelos } \\
\text { trabaihadores queaexeattam }\end{array}$ \\
\hline RESUITADOS & maisespecficons & maisgerais \\
\hline
\end{tabular}


Estado de São Paulo solicitou-nos um parecer sobre o assunto (Ferreira et allii, 1991).

Após contatos iniciais com a direção da empresa e com os operadores envolvidos e pesquisas na literatura técnica sobre o assunto, nossa equipe decidiu: 1- que a questão central a ser respondida era a justificativa ou não da redução dos efetivos nessa unidade, 2- que o método a ser utilizado seria a AET, conforme já foi definida.

\section{Critérios para a Definição do} Efetivo de uma Unidade de Processo Contínuo

Os critérios existentes para a determinação do efetivo de uma unidade de processo contínuo são empíricos e variam de uma empresa para outra. $\mathrm{Na}$ prática, há uma tendência de se copiar o que ocorre em unidades semelhantes, $o$ que não deixa de ser problemático, uma vez que isto exige se definir os pontos de semelhança e diferença a serem comparados.

No presente caso, o documento Reanálise dos Efetivos de Turnos (citado em Ferreira et allii,1991) mostrava como a empresa pensava na época do estudo. A partir de uma análise sobre a oportunidade de uma redefinição dos efetivos das unidades operacionais, "tendo em vista as mudanças constitucionais e uma necessidade de reformulação administrativa que levasse a um maior desempenho global da empresa, com redução de custos e racionalização de recursos," concluía-se que "a reanálise e o redimensionamento de efetivos deveria ser realizado alguns anos após a partida da unidade face à:1-Normalização da operação da unidade; 2-Existência de procedimentos, rotinas e "check list"consolidados; 3 -Perfeito conhecimento de todos os componentes dos grupos de turnos; 4-Grande aumento da experiência e habilitação do pessoal de turno; 5-Introdução de melhorias operacionais/ou inovações tecnológicas; 6-Existência de cultura local própria; 7 Reposição de pessoal sendo realizada com pessoal de melhor qualificação."

Resumindo, o raciocínio da empresa era o de que sendo a definição dos efetivos de turnos realizada na fase de préoperação das unidades, com pessoal novo e inexperiente, seria natural que seu número se reduzisse na medida em que houvesse, por um lado, melhorias no processo de produção e por outro lado, major experiência dos operadores. Seguindo este raciocínio, que em suas bases nos parecia razoável, fomos a campo para verificar como estavam as condições da unidade segundo os pontos mencionados.

\section{As Condições da Unidade}

Ao analisar as condições da unidade, chegamos às seguintes conclusões: 1-Nos seus sete anos de existência, a unidade não tinha se modernizado, ou seja, não tinha havido implementação de inovações tecnológicas ou introdução de melhorias 
organizacionais significativas.2-Também não tinha havido "normalização da operação". Ao contrário, o número de paradas de emergência e anormalidades operacionais tinha crescido nos últimos anos.3-A unidade era de alto risco e a empresa não tinha implementado uma série de dispositivos de segurança propostos para melhorar suas condições de segurança .4-Cada equipe de turno possuia 8 operadores, ao invés dos 11 iniciais. Metade destes operadores nela trabalhavam desde a época de sua instalação, mas entre os demais, cerca de um terço tinha um tempo de serviço igual ou inferior a 3 anos.

Assim, se era inegável que uma parte dos operadores conhecia melhor a unidade por estar nela trabalhando desde o início de seu funcionamento, por outro lado também era inegável que a unidade apresentava uma série de problemas operacionais que, ao longo do tempo, não só não tinham sido resolvidos como vinham se agravando.

Deste ponto de vista, seguindo o próprio raciocínio da empresa, a maior experiência estava de certa forma sendo contrabalançada pelo maior número de problemas. Até que ponto? Esta nova questão nos remetia a entender as tarefas e as atividades desenvolvidas pelos operadores da unidade.

Tarefas e Atividades dos Operadores: um Trabalho de Equipe

Para se entender as tarefas e as atividades dos operadores, precisa-se conhecer algumas das características dos processos de produção de unidades de refino: $1-O$ processo utiliza grandes volumes de matérias primas e se dá em um conjunto complexo de numerosos equipamentos interligados, que ocupam grandes espaços, 2-em geral, as substâncias utilizadas são perigosas, porque explosivas e/ou tóxicas, 3-a maior parte do controle do processo é indireto e se faz à distância, através de painéis de controle ou de computadores, 4-o processo é contínuo, isto é, não se interrompe, embora seja composto por etapas diferentes, onde ocorrem reações físicas, químicas ou fisico-químicas definidas, em condições e em tempos bem definidos, 5-o volume produzido não é diretamente dependente do número de operadores envolvidos, 6-o número de operadores efetivamente presentes para controlar o processo é baixo: há várias unidades que funcionam com apenas 2 ou 3 operadores por turno.

Estas características diferenciam os processos contínuos dos processo de fabricação em série e fazem com que as tarefas e atividades dos operadores nos dois casos sejam fundamentalmente diferentes. Nos processos contínuos, tratase, antes de tudo, de um trabalho de equipes que se revezam ao longo dos dias e das noites, sem parar.

\section{As Equipes de Turno}

Cada equipe de turno é um conjunto de operadores, fixos e em número préestabelecido, com diferentes qualificações formais, que se distribuem espacialmente 


\section{PRODUÇÃO}

na área de trabalho da unidade, composta basicamente da sala de controle e da área de processo. Os operadores têm obrigatoriamente que cooperar entre si.

Esta equipe tem como objetivo produzir determinados tipos de produtos na quantidade e com a qualidade exigidas pelos órgãos de direção, a partir de ordens de serviço recebidas periodicamente. Ora, para que este objetivo seja cumprido satisfatoriamente, é indispensável que todo o dispositivo tecnológico esteja funcionando perfeitamente, isto é, que as matérias primas estejam chegando no momento certo, com a qualidade exigida e na quantidade exigida; que todos os numerosos equipamentos onde ocorrem as reações estejam funcionando bem, que toda a circulação de produtos, feita através de tubulações, esteja em ordem; que todos os serviços auxiliares- "as utilidades"- que garantem o fornecimento de eletricidade, água, ar comprimido estejam funcionando a contento, que todo o sistema de controle, composto por centenas de instrumentos, esteja funcionando sem problemas e que tudo isto esteja funcionando integradamente. Isto significa que cabe aos operadores controlar todos os pontos do sistema e intervir prontamente sobre ele, caso detectem alguma anormalidade. Neste caso, dependendo do caráter da anormalidade, eles podem saná-las ou pedir que outros setores da empresa o façam. É óbvio também que, na medida em que o sistema esteja degradado as tarefas dos operadores aumentem em número e complexidade.
Um conceito importante para se compreender o que se passa em uma unidade de refino é o de acontecimento, isto é, um evento ou uma série de eventos encadeados que geram uma situação nova ou inesperada, conhecida ou desconhecida pelos que devem enfrentá-la. Devido ao grande número de variáveis que intervêm no processo, nele estão sempre surgindo novos acontecimentos e a "missão" principal dos operadores é zelar para que estes acontecimentos não ocorram ou, se não for possível, minimizar os seus efeitos, de modo que eles não provoquem nem perdas materiais (de produtos e de tecnologia) nem perdas humanas.

\section{Comunicações no Trabalho}

Num trabalho de equipe, a comunicação é fundamental. Esta comunicação se dá tanto entre os operadores de turno como entre estes e os membros de outros serviços da empresa e mesmo de fora dela, através de falas (diretamente ou por meio de aparelhos como telefones e rádios), de documentos escritos (quadros, formulários, relatórios, livros, bilhetes,etc) e até de gestos.

Para se apreender a importância das comunicações na equipe da unidade que estávamos analisando, fizemos vários registros de comunicações verbais, em diferentes situações e entre diferentes interlocutores. Nas situações calmas, as comunicações eram relativamente escassas, mas bastava haver algum incidente para que elas se intensificassem. Os interlocutores eram em geral os 
operadores de painel e os de campo, que passavam todo o tempo se comunicando entre si. $O$ operador chefe era também muito acionado e se comunicava não só com o pessoal de sua equipe como com o pessoal externo à sua unidade. $O$ engenheiro chefe da unidade praticamente não era acionado.

Mas, sobre o que falavam os operadores? As trocas de informações entre os diferentes operadores envolviam as seguintes funções, imprescindíveis para o controle do processo: 1-conhecer o estado da unidade, para planejar as operações a serem realizadas; 2-coordenar operações simultâneas ou sequências de operações; 3-tirar dúvidas; 4-resolver problemas; 5certificar-se das atividades realizadas pelos colegas; 6-dar ou receber ordens; 7autorizar serviços de pessoas estranhas à unidade.

As comunicações no trabalho também funcionavam como um meio de garantir a homogeneidade dos conhecimentos sobre o funcionamento do sistema entre todos os membros da equipe, o que é fundamental num trabalho de equipe.

O estudo das comunicações mostra claramente que um trabalho de equipe não é apenas a soma de trabalhos individuais mas a integração destes trabalhos. A comparação com um time de futebol é esclarecedora: um time não é só composto por 11 jogadores que ocupam diferentes posições dentro do gramado; é também a relação que se estabelece entre todos os jogadores, em função, também, do time adversário.
A Inadequação da Utilização dos Métodos de Estudo de Movimentos e Tempos nas Indústrias de Processo Contínuo.

O estudo das atividades reais dos operadores mostrou como é falsa a idéia de que seu trabalho consiste simplesmente em controlar um processo automatizado que funciona perfeitamente, como parece ser o pensamento dominante entre os organizadores do trabalho. São raros os períodos em que a atividade dos operadores se restringe a uma atividade de vigilância. Ao contrário, há, em geral, uma intensa atividade de busca de informações através de consultas a documentos ou de comunicações com outras pessoas $e$ há frequentes interrupções para se atender a acontecimentos inesperados que surgem. Há também uma intensa atividade de intervenção no sistema. acompanhamento dos operadores na área de processo e na de estocagem de produtos revelou que eles têm que intervir diretamente nos equipamentos- abrir e fechar válvulas, subir em torres, tirar amostras de produtos, inspecionar longos trechos de tubulações, etc.

Isto significa que a mais utilizada técnica da engenharia de produção para analisar o trabalho e determinar seus tempos e número de trabalhadores- o Estudo de Movimentos e Tempos (EMT) e suas variações mais recentes- não se aplica na análise do trabalho de uma equipe de turno em processo contínuo. Por que? Porque ela foi feita para avaliar 


\section{PRODUÇÃO}

tarefas individuais, bem precisas no tempo e no espaço e de expressão essencialmente motora e não tarefas coletivas, não muito delimitadas e essencialmente cognitivas.

No caso em questão, fizemos algumas comparações entre as prescrições de tarefas feitas pelas chefias- baseadas no estudo de movimentos e tempos - e as atividades realizadas pelos próprios operadores em várias situações. Em todas elas detectamos uma enorme diferença. Os "tempos a disposição" que na análise prescrita chegavam a $60 \%$ em algumas situações, na verdade foram em todos os momentos utilizados e preenchidos. Além disso, encontramos várias situações onde havia uma nítida sobrecarga de trabalho e uma superposição de tarefas para um mesmo operador, obrigando-o a optar por uma delas em detrimento de outras e levando a uma preocupação adicional em relação a pertinência da escolha feita.

\section{Problemas Detectados com a Diminuição de Efetivos}

Com a diminuição de efetivos e o aumento dos problemas a serem enfrentados, diminuía a margem de manobra dos operadores para controlar a unidade e aumentava a incerteza sobre o funcionamento do sistema, porque eles tinham que priorizar ações e fazer escolhas, uma condição extremamente difícil dadas as características perigosas e complexas do sistema. De fato, os operadores não podem deixar de fazer determinadas tarefas pois delas dependem a sua segurança e a da unidade, e sua responsabilidade profissional é grande.
Isto cria uma situação extremamente conflitante e aumenta a ansiedade, que é inerente a todos os que trabalham em processos perigosos (Wisner et allii, 1987; Dejours, 1992). Ora, é extremamente preocupante e grave que um sistema tão perigoso seja controlado por uma equipe sobrecarregada e ansiosa.

\section{Respondendo à Questão Inicial}

A análise ergonômica que realizamos indicou que até pelos próprios parâmetros da empresa, a diminuição de efetivos não se justificava. De fato, a unidade não só não tinha seu funcionamento normalizado como apresentava sérios problemas, obrigando os operadores, em número reduzido, a uma sobrecarga de trabalho. A justificativa da empresa sobre o tempo ocioso dos trabalhadores não encontrou nenhum respaldo na realidade. Foi esta a conclusão final do estudo, enviada para o Ministério Público'. No entanto, algumas questões subsistem: por que a empresa insistia em diminuir os efetivos?

Encontramos pistas para esta resposta no próprio documento da empresa, já citado, especificamente quando dizia da oportunidade de se redimensionar os efetivos para adequação ao novo dispositivo constitucional (BRASIL,1988) que regulamentava a jornada de trabalho para processos contínuos, em turnos de revezamento: esta jornada passaria de 8 para 6 horas, numa espécie de compensação para os efeitos negativos do trabalho em turnos para os trabalhadores. Em termos práticos, esta redução da jornada implicaria a contratação de novos operadores: 5 equipes de 6 horas ao invés de 4 equipes de 8 horas. Ora, a 
necessidade de contratações não estava nos planos da empresa. Pelo contrário, ela pretendia reduzir custos, o que na atual política industrial brasileira é quase sinônimo de "enxugamento" de quadros. Aliás, um dos argumentos usados era a de que outras unidades em países do "primeiro mundo" o número de operadores era menor. Assim, ao invés de contratar mais uma equipe, a decisão da empresa foi a de redistribuir o efetivo total de operadores em 5 equipes, obviamente cabendo a cada uma um número menor de operadores. Foi esta redução que iniciou o conflito.

Além de compreender melhor as origens deste conflito, nosso estudo revelou outros de seus aspectos: a contraposição entre duas concepções diferentes de trabalho: o da empresa e o dos trabalhadores. Estas diferenças provocavam diferentes modos de se analisar a atividade e, consequentemente, diferentes propostas quanto ao número de operadores necessários. Para a empresa, tratava-se de "racionalizar"o trabalho e acabar com a "ociosidade". Para os trabalhadores, não havia ociosidade, muito pelo contrário, havia sobrecarga. Para a direção, o trabalho era um problema; para os operadores, a solução.

O quadro abaixo, contrapondo concepções sobre o trabalho de operadores e direção, resume como percebemos estas diferenças:

\begin{tabular}{|c|c|}
\hline DIREÇĀO & OPERADORES \\
\hline $\begin{array}{l}\text { riscos sob controle, desde que se respeite as normas } \\
\text { de segurança }\end{array}$ & $\begin{array}{l}\text { riscos podem fugir ao controle mesmo que se } \\
\text { respeite as normas de segurança }\end{array}$ \\
\hline $\begin{array}{l}\text { funcionamento do dispositivo tecnológico } \\
\text { normalizado }\end{array}$ & $\begin{array}{l}\text { funcionamento do dispositivo tecnológico não } \\
\text { normalizado }\end{array}$ \\
\hline $\begin{array}{l}\text { funcionamento do dispositivo tecnológico com } \\
\text { poucas variações }\end{array}$ & períodos perturbados $\mathrm{X}$ períodos calmos \\
\hline poucas tarefas, aparentemente simples & muitas tarefas, às vezes de alta complexidade \\
\hline alocação de tarefas entre operadores bem delimitada & limites das tarefas de cada operador não tão nítidos \\
\hline tempos precisos para cumprir cada tarefa & tempos variáveis e nem sempre programáveis \\
\hline modos operatórios fixos e repetitivos & modos operatórios variáveis e heurísticos \\
\hline predomínio de tarefas de simples vigilância & $\begin{array}{l}\text { predomínio de tarefas de planejamento e } \\
\text { intervenção. }\end{array}$ \\
\hline $\begin{array}{l}\text { não considera variações do estado dos operadores } \\
\text { pela ritmicidade biológica }\end{array}$ & $\begin{array}{l}\text { grandes alterações no estado dos operadores } \\
\text { segundo os diferentes turnos }\end{array}$ \\
\hline gestão baseada em hierarquia & gestão coletiva do processo \\
\hline valorização do desempenho individual & valorização da experiência prática coletiva \\
\hline $\begin{array}{l}\text { trabalho da equipe = somatório dos trabalhos } \\
\text { individuais }\end{array}$ & $\begin{array}{l}\text { trabalho da equipe }=\text { integral dos trabalhos } \\
\text { individuais. }\end{array}$ \\
\hline
\end{tabular}




\section{PRODUÇÃO}

O estudo também mostrou a pertinência da Análise Ergonômica do Trabalho na questão da determinação de efetivos, um tema ainda relativamente pouco explorado por ergonomistas (Duarte, 1994).

\section{O Segundo Estudo: ACT e o Trabalho dos Petroleiros}

O segundo estudo surgiu da confluência de interesses de duas instituições: uma, de pesquisa- estávamos querendo aprofundar nossos estudos na área do petróleo- e a outra sindical, preocupada com as condições de trabalho da sua categoria. Nosso objetivo era conhecer melhor a atividade dos trabalhadores no petróleo, a partir do que eles próprios poderiam nos falar sobre ela.

O método utilizado foi o da Análise Coletiva do Trabalho (ACT) como já foi apresentada no início deste artigo, onde trabalhadores descrevem seu trabalho, o mais pormenorizadamente possível, para um grupo de colegas e de pesquisadores ergonomistas, que têm a função de ajudálos nesta descrição, colocando questões pertinentes. $O$ processo de reuniões, na sede do Sindicato, se estendeu por vários meses e mais de cinquenta trabalhadores de uma refinaria e de dois terminais marítimos dele participou. No final, um relatório (Ferreira e Iguti, 1994) foi entregue para a diretoria do Sindicato.
Quanto aos resultados obtidos, podemos agrupá-los em duas grandes categorias: aqueles específicos de um grupo de trabalhadores em determinada situação de trabalho, e aqueles mais gerais, de alguma forma comuns a todos os trabalhadores. Neste texto, vamos nos ater aos resultados mais gerais.

\section{Características Gerais do Trabalho no Petróleo: Perigoso, Complexo, Contínuo e Coletivo}

$O$ primeiro resultado interessante deste estudo foi o de generalizar, para todo o universo estudado, as cararacterísticas do trabalho já esboçadas no estudo anterior. De fato, quer o trabalho se passe numa refinaria ou terminal, ele é um todo onde quatro diferentes aspectos- ser perigoso, complexo, contínuo e coletivose integram, entram em ressonância uns com os outros (é lógico que em diferentes proporções e de acordo com a especificidade da unidade produtiva em questão), de modo que alterações em cada um deles se refletem em todos os demais. Por exemplo, quando se altera a composição de uma equipe de turno, se altera a complexidade do trabalho e o controle de seu risco. Isto não acontece em todos os processos de trabalho. Nas indústrias de produção em série, as características do trabalho são bem diferentes destas. E mesmo em outras indústrias de processo contínuo, o grau destas características e a sua proporção no trabalho são diferentes. 
O segundo resultado interessante foi também o da generalização de alguns problemas vistos como particularidades no primeiro estudo: a preocupação com a diminuição de efetivos nas unidades operacionais e com a terceirização dos serviços de manutenção. Eles adquiriam graus diferentes nas diferentes unidades mas estavam presentes em todas elas.

A seguir, vamos apresentar alguns dos pontos que se destacaram, sempre tendo em vista que o objetivo do estudo era conhecer a atividade realizada pelos trabalhadores, a partir da descrição feita por eles próprios( grafadas no texto com caracteres itálicos).

\section{Um Trabalho Perigoso}

A primeira característica do trabalho com o petróleo é o perigo:

"Em uma refinaria de petróleo a gente costuma dizer que trabalha em cima de uma bomba!".

"O terminal é uma bomba."

Em primeiro lugar, há o perigo de incêndios e explosões, que podem acontecer a qualquer momento, inesperadamente:

"No caso da estocagem do GLP [gás liquefeito de petróleo], a gente trabalha com uma pressão máxima de 90 gramas. Acima de 90 gramas, ele abre para a tocha. Acima de 104 gramas ele abre para a atmosfera. Quando o ponteiro está chegando próximo destes números, a frequência cardíaca já aumentou bastante. $O$ maior perigo do terminal é esse: abrir para a tocha e depois abrir para a atmosfera, pois estariamos pondo em risco a sociedade toda, a cidade toda. Porque lá estão armazenados dez mil toneladas por tanque!"

Outro grande perigo são os grandes vazamentos de produtos tóxicos que podem provocar acidentes fatais e que, felizmente, têm sido raros no Brasil mas não em outras refinarias no mundo. $O$ que é muito mais comum são os pequenos vazamentos que ocorrem quase o tempo todo:

"Sempre há vazamentos; é praticamente impossivel não existir vazamentos numa refinaria."

Na verdade, todo o trabalho com o petróleo é perigoso e insalubre. Existem riscos decorrentes do próprio processo e da toxicidade dos produtos nele utilizados, além dos' riscos não específicos, como ruídos elevados, muito calor, acidentes do trabalho típicos.

Todos os funcionários são treinados para enfrentar as situações de emergência e os perigos que elas comportam:

"Quando a gente entra para trabalhar, no primeiro dia de serviço, os mais velhos dizem assim: 'cuidado, porque o nosso serviço não tem borracha que apague. Você errou, aparece'. Esta é a primeira lição." 


\section{PRODUÇÃO}

"A pessoa normal vê um fogo e corre. Nós, não. A gente vê um problema na nossa area, o nosso instinto é preservar aquilo...A gente sabe o risco que corre, mas a gente faz".

A ética profissional e a responsabilidade por vidas humanas permeia o dia a dia dos operadores e provoca um estado de tensão constante:

"O problema todo é a tensão que a gente passa. Você sabe que trabalha num lugar que explode, pega fogo. Isso fica no inconsciente da pessoa".

"Sua ética profissional empurra você. Faz parte da sua função."

\section{Um Trabalho Complexo}

As características das tarefas dos operadores se enquadram perfeitamente no que se define como tarefas complexas (De Montmollin, 1986), porque trata-se de controlar um sistema complexo. Em primeiro lugar, eles têm que lidar com uma grande quantidade de variáveis. Os painéis de controle de uma unidade de refino, por exemplo, registram centenas, às vezes milhares de variáveis, as quais podem adquirir inumeráveis configurações cada uma delas representando uma situação diferente.

"Operação é um negócio extremamente complexo, a cada instante você está numa situação."

Muitas destas variáveis estão em íntima relação e interação de modo que alterações em cada uma delas repercutem nas outras. Além disso, em geral não se trata apenas de constatar a presença ou ausência de uma indicação mas de seguir sua evolução.

"Quando o operador tem muito tempo na unidade, variou determinada coisa, ele percebe. Ele olha automaticamente para onde deve estar aparecendo o reflexo daquela variação."

Outra característica importante é o caráter simbólico das variáveis transmitido por um segundo tipo de tratamento da informação, também complexo:

"Quando você mexe num instrumento no painel, você está raciocinando: eu estou mexendo nesse instrumento mas estou mexendo em tal válvula lá fora. Quando você mexe no painel, você automaticamente está enxergando até a válvula na imaginação."

A terceira característica das tarefas em um sistema complexo é o caráter aleatório e imprevisível dos acontecimentos, que não podem ser deduzidos de uma lei determinista. Esta imprevisibilidade é intrínsica e não uma falha do sistema. As emergências são exatamente os resultados graves desta imprevisibilidade :

"Eles dizem que a unidade não foi feita para entrar em emergência. Concordo plenamente. Mas ela entra."

Isto faz com que os operadores devam estar alertas o tempo todo para detectar os pontos de disfuncionamento, saná-los e evitar que uma pequena falha se torne um grande problema. 


\section{PRODUÇÃO}

"O bom seria se se pudesse trabalhar na frente dos acontecimentos, antes de acontecer."

Outra característica de um sistema complexo é que nele os fenômenos podem evoluir lenta e invisivelmente. Finalmente, num sistema complexo, há simultaneidade de tarefas. Não são raras as ocasiões em que situações diferentes, cada uma com sua própria lógica, ocorram simultaneamente.

"Se só tem uma pessoa e essa pessoa tem que atuar em dois lugares, o que ela faz? Não faz nada? Faz um? E o outro?"

Tarefas complexas determinam atividades complexas. A dos operadores, muito mais do que aplicar uma série de procedimentos prescritos, é compreender as situações que se engendram no decorrer do processo, a partir da análise feita com todas as informações disponíveis, para poder intervir satisfatoriamente. $\mathrm{O}$ que realça o papel insubstituível da experiência:

"Porque a gente tem experiência, chega na frente do equipamento, põe a mão, vê se não está vibrando, se ele não está com ruído anormal. Você usa tudo que é sentido."

"Existem situações em que ninguém entende bem o que está se passando. principalmente quando a unidade énova. Alguma coisa acontece uma vez, você sai fora. Acontece a segunda: 'ôpa, aconteceu daquela vez, nós saimos fazendo isso e isso.' Você vai associando...'
É por isso que o tema da formação, do saber dos trabalhadores e do tempo necessário para se tornar um bom operador ocupa um lugar central na vida dos petroleiros:

- "Quando eu entrei, a gente não tinha o menor entendimento daquilo lá. Aquilo lá assusta! Assusta todo mundo que vai trabalhar lá. A adaptação, vai um tempo longo. A gente falava: você forma um operador, um bom operador, em 6 anos. Hoje eles[a chefia] acham que formam em 6 meses."

"Para a pessoa assimilar uma unidade, ela tem que pegar muita emergência. É aí que pega a experiência da unidade, pega o macete da unidade, quando ele pega o problema da unidade. Como eu tenho dezessete anos de experiência, eu sei dominar a unidade."

Além do longo tempo de prática, um bom operador deve ter interesse, curiosidade, vontade de aprender, coleguismo, iniciativa. E principalmente, a compreensão de todo o processo:

"Para a formação do operador, para ele ser um bom operador, ele precisa conhecer todo o processo. Quanto mais um operador entender o processo todo, mais ele vai operar com excelência."

Finalmente, aponta-se uma última característica do bom operador: fazer um belo trabalho:

"O problema não é só fazer certo. É fazer bem. Então, é o pessoal que quer chegar mais perto da perfeição". 


\section{PRODUÇÃO}

É ilustrativa a comparação feita por um operador entre seu trabalho numa unidade de refino e aquele de um piloto de avião:

"Um vôo de cruzeiro é a unidade. operando normalmente. Uma turbulência é uma emergenciazinha. Uma emergência grave é a queda do avião. A decolagem e a aterrissagem são a partida e a parada, a hora mais crítica. O risco é igual. A partir do momento em que o piloto aciona o motor do avião, que ele está taxiando, é a hora que nós estamos circulando a unidade. A hora que ele vai para a cabeceira da pista é a hora em que a unidade está em ponto de pegar carga. $A$ hora em que ele começar a acelerar o avião para levantar vôo, a carga está lá. Ai, só basta estabilizar o curso. $\mathrm{Na}$ aterrissagem é a mesma coisa: ele vem vindo, ai ele começa a perder a altitude, a gente começa a reduzir a carga. O ponto crítico onde é? Onde ele bate no chão, onde ele vê a pista na frente dele. Às vezes, ele vê a pista e não pode aterrissar: ele tem que dar outra volta. Às vezes, a gente também vê isso: a unidade vem parando- 'não, não pára porque surgiu um problema!'-tem que ter a manutenção. $E$ isso que acontece. Nada mais do que isso... Nosso erro pode ser fatal como um erro do piloto é fatal."

\section{Um Trabalho Contínuo}

Como a produção não pode parar, são os operadores que têm que se revezar para acompanhá-la. É o pessoal da área de operação da refinaria e dos terminais que trabalha e vive neste sistema de turnos rodiziantes.

A jornada começa com a passagem de turno, um momento essencial para que os operadores conheçam a situação da unidade e se preparem para enfrentá-la:

"Quando a pessoa vem me render, a gente passa o que está andando de trabalho e o que aconteceu de diferente, se parou equipamento, onde está a operação crítica, se aconteceu um problema aqui, que vai gerar isso e isso, ou que você analisou. Então, você alerta a pessoa onde é que estão os riscos. onde é que estão as prioridades."

Trabalhar em sistema de revezamento de turno é penoso porque interfere nos mecanismos básicos de funcionamento humano, que fazem com que estejamos em estados funcionais diferentes de acordo com as horas do dia, fundamentalmente que estejamos prontos para atividades durante o dia e para o repouso durante a noite. Quando se troca o dia pela noite, como acontece com quem trabalha em turnos de revezamento, aparecem alterações na vigília e no sono: sente-se dificuldade de se dormir de dia e sono durante o turno da noite:

"Para a grande maioria, o pior horário é zero hora [turno da madrugada]. Ele te dá uma moleza, um desânimo maior. A hora crucial é quatro horas da manhã. Passou das quatro, está tudo bom". 
"Quando começava a me dar sono, eu dizia para o operador chefe: 'deixa eu dar uma volta, porque o troço hoje está feio'...Você vai, sobe no forno, desce, porque, se parar, dorme."

A maioria dos turnistas não se acostuma com a mudança de horário:

"Tem gente que trabalha vinte anos de turno e não consegue se acostumar com a zero hora. Quando está começando, lá pelo terceiro ou quarto dia, vem a troca de turno. Tem gente que não consegue, não dorme, tem insônia".

Para lutar contra esta insônia, os operadores empregam várias táticas, todas elas insatisfatórias:

"Quando eu trabalho zero hora, para dormir de manhã é pior, a não ser que tome uns conhaques. Lá, muita gente faz. isso."

Para outros ,que procuram assistência médica, às vezes são receitados soníferos:

"Você toma meio comprimido $e$ dorme. Ai, toma meio comprimido e não dorme. Você vai ao médico e toma um comprimido e dorme... Eu parei quando o médico me mandou tomar três. Porque é uma dependência, você passa por um processo terrivel..."

Além destes efeitos fisiológicos, a vida social e familiar dos trabalhadores é prejudicada.
"A sua mulher acaba trabalhando em turno também."

\section{Um Trabalho Coletivo}

Uma das características mais marcantes da indústria do petróleo é a inter- dependência de serviços, em todos os níveis. Começando por um nível mais estrutural, há uma grande inter-relação entre refinarias e terminais. Dentro de cada refinaria, várias unidades de processamento estão interligadas entre si, sem contar a interrelação obrigatória delas com os serviços de utilidades. Estas relações funcionais entre diversas unidades- conferindo ao sistema como um todo o aspecto de malha- se refletem na atividade dos petroleiros. Ela é coletiva por excelência. E se pudéssemos representar graficamente as inter-relações que existem entre as atividades destes trabalhadores, veríamos que elas engendrariam uma malha ainda mais sofisticada.

Uma unidade de processo só funciona porque há uma equipe de pessoas, distribuindo entre si as inúmeras tarefas que têm de ser feitas. Esta equipe, por sua vez, se relaciona com outras equipes, da mesma ou de outras refinarias e terminais.

"O negócio tem que ser em cadeia. Não adianta você dar uma de herói, que não tem jeito. Você depende do Laboratório, da Casa de Força, da Manutenção, depende também do pessoal da instrumentação..." 
Nos terminais marítimos, a situação não é diferente.

Um importante aspecto do coletivo é a composição das equipes de operação. Operadores com diversos graus de formação precisam atuar harmonicamente

“Operação é um grupo, não é só um. São várias cabeças pensando, trocando idéias."

Por isso compreende-se porque os trabalhadores são tão sensíveis às intervenções impostas pela direção sobre as equipes de trabalho, sejam elas trocas de pessoas, alterações nas qualificações ou diminuição de efetivos. É que cada mudança implica numa reestruturação de todo o coletivo e da atividade de trabalho de cada um. A diminuição de efetivos operacionais e a terceirização de serviços de manutenção, alterando as relações de trabalho, foram temas presentes em todo o processo de ACT e por isso vamos aqui nos deter sobre eles.

\section{Diminuição de Efetivos Operacionais}

A diminuição de efetivos operacionais faz parte da política de modernização da empresa e a tem atingido como um todo principalmente a partir de 1990 . Segundo dados da própria empresa (Petrobrás, 1993), de 1982 a 1989 houve um aumento de aproximadamente $20 \%$ de seu efetivo total, que passou de 50132 para 60028 funcionários. A partir de 1990, a política de "enxugamento" de quadros anulou este aumento de modo que em
1993 o efetivo total da empresa era $20 \%$ inferior ao de 1990, alcançando 50466 funcionários. Na refinaria estudada, o efetivo passou de 2270 em 1987 a 1608 , em junho de 1993, com uma redução de cerca de $30 \%$, isto é, maior do que a média da empresa (Ferreira e Iguti,1994). Esta redução de quadros se deu basicamente porque a empresa não tem contratado funcionários para repor aqueles que se aposentam; pelo contrário: ela até incentiva o pessoal à aposentadoria.

Para compreender os depoimentos que se seguem, será necessário compreender o que significa, na terminologia da empresa, a expressão quadro mínimo: "o menor número de elementos por grupo de turno efetivamente necessário para a execução de tarefas sistematizadas que leve certa unidade a uma condição segura em caso de emergência". A definição de quadro mínimo é importante porque a equipe de turno só pode trabalhar se tiver seu quadro mínimo completo. Caso contrário, um elemento do turno anterior é obrigado a substituir o que falta, isto é, dobrar o turno. Teoricamente, o efetivo por turno é calculado sobre o total deste quadro mínimo, levando-se em consideração as necessidades de férias, absenteísmo e treinamento de pessoal.

Em quase todas as unidades operacionais o quadro mínimo foi diminuído. Esta questão é penosamente vivida pelos trabalhadores:

"A minha maior apreensão dentro da refinaria é o seguinte: com a redução do 
quadro mínimo, cai a qualidade da rotina. E a rotina é uma coisa importantíssima. porque durante as rotinas feitas todos os dias, você vai detectando problemas futuros e agravamento de problemas. Só com a rotina..."

"Minha maior preocupação é a rotina. Diminuindo o número de pessoas, deve cair a qualidade da rotina. $E$ cai. $\dot{E}$ provado como $I+I=2$. Isso eles não querem enxergar...Há mais serviço de manutenção e diminuição do ciclo de operação. Por uma rotina mal feita, eu levo uma unidade a emergências mais constantemente. Toda vez que a unidade entra em emergência, o desgaste da unidade é maior."

"Nossos piores momentos são as emergências, onde a gente tem que se desdobrar realmente e com a redução de quadro cada vez mais a emergência vai se tornando um problema maior, apesar do desenvolvimento da tecnologia, como eles falam, para dar alta confiabilidade no sistema. Mas tem hora que tem que ser manual, e o desdobramento é muito maior."

"O quadro mínimo era seis e agora ficou cinco. Quando o quadro mínimo era seis, todo o dia tinha dobra, em todos os grupos, pelo menos uma. Eles reduziram o quadro para evitar essas dobras...Porque quando baixa o efetivo mínimo, deixa de dar dobra, eles cortam homem-hora. Cada vez que um dobra, são doze horas a mais, porque ele está ganhando a jornada dele mais outra jornada, 100\%."
"Quando dobra, não dá para explicar. Chega um ponto em que o cara vira um zumbi. Comeca a falar nada com nada. Fica doido. E pior: ele traz aquele problema para dentro de casa também. Ele briga com a mulher, briga com os colegas, é uma barra!"

\section{A Terceirização dos Serviços de Manutenção}

Simultaneamente à redução dos quadros de funcionários da empresa, houve um aumento na contratação de empregados de outras empresas, as "terceiras" ou as "empreiteiras" para realizarem serviços que até então eram feitos pelos próprios funcionários. $\mathrm{Na}$ época do estudo, a maioria dos serviços de manutenção estava na mão das empreiteiras, onde trabalhavam, só na refinaria, 3000 pessoas e mais de 1000 nos terminais. Ou seja, na refinaria havia quase 2 empregados de empreiteiras para cada funcionário da empresa e nos terminais a proporção era ainda maior.

Além de criar situações constrangedoras na convivência de trabalho, pela enorme diferença em termos de qualificação e cobertura social entre os dois tipos de trabalhadores, a terceirização tem repercussões na atividade de trabalho dos funcionários.Para os da operação, ela representa uma fonte a mais de preocupação e exige um aumento da vigilância. Para os funcionários da manutenção que restam, há uma mudança de função: eles passam a executar tarefas de supervisão das 


\section{PRODUÇÃO}

empreiteiras e muitos reclamam que querem trabalhar mais:

"O absurdo que se passa: eu sou mecânico, mas nós não exercemos a nossa função porque tem empreiteira para fazer. Então, a gente vai supervisionar e ver o que a empreiteira vai fazer. Ao mesmo tempo, a empreiteira não tem mais o carinho com o equipamento que a gente tem. Eu conheco parafuso a parafuso, eu conheço o equipamento há mais de vinte anos. A gente tem condições de exercer essa função; se levar um ajudante comigo, exerço toda a função bonitinho, conserto o equipamento. Só que não sei porque cargas d'água, isso é empreiteira e a gente vai supervisionar empreiteira."

Ora, o serviço de manutenção é estratégico na indústria do petróleo, porque falhas no funcionamento dos equipamentos e instrumentos podem provocar interrupções mais ou menos longas na produção e até acidentes, com grandes perdas de material e humanas. Além disso, trata-se de um serviço altamente especializado, que exige uma longa formação e experiência prática:

"Quando o quadro de manutenção é da refinaria, ele é especializado. Trabalham com aqueles equipamentos dez, quinze, vinte anos, conhecem a manha do equipamento. Na empreiteira, o que acontece? Um dia vem um $e$ conserta. Não fica bom. Passa uns tempos, vem outro. Então, embora a gente oriente, eles não têm a mesma capacidade. Porque não pode ter a mesma capacidade aquele que trabalha com aquela máquina um ano e um que trabalha vinte anos. Essa é a diferença."

\section{Uma Situação Brasileira}

Às quatro características do trabalho dos petroleiros anteriormente descritas, se deve incluir, no caso brasileiro, o fato dele se desenvolver numa só empresa, estatalna realidade, a maior empresa do Brasilcom uma só cultura e com uma história que sempre se confundiu com a História do Brasil. Desde sua criação, que foi fruto de uma intensa mobilização nacional pelo monopólio do petróleo há quarenta anos, os trabalhadores se sentiram coparticipantes não só de seu destino como dos do país. Diz um aposentado:

"O que fazia com que o trabalhador trabalhasse satisfeito era uma palavra só que puseram na nossa cabeça. Sabe qual foi? O petróleo é nosso e daqui nós vamos ser a maior potência do mundo! Era isso que fazia com que o trabalhador trabalhasse de dia e de noite, sem reclamação."

Durante todo nosso estudo, este envolvimento se fez sentir, embora de modo contraditório: na forma de orgulho e de amor pelo trabalho e pela empresa ou na forma de insatisfação pela situação em que estavam vivendo, fruto de uma nova política da empresa, inserida por sua vez numa nova política governamental para o país e para o petróleo. ${ }^{2}$ 


\section{PRODUÇÃO}

'Eu acho que primeiramente, nós somos nacionalistas. Eu gosto daquilo lá, eu adoro aquilo lá, apesar de tudo. Nunca eu iria deixar o equipamento pegar fogo!"

"Eu gosto do serviço que eu faço, eu gosto da companhia, sempre tive vontade de trabalhar lá quando eu era pequeno. Eu pensava assim: 'qualquer dia, eu vou trabalhar na refinaria'. Porque a [empresa] sempre se destacou no Brasil. Eu tinha vontade de ver esse negócio do petróleo, até tér tido a sorte de entrar...Mas que alguém está querendo terminar com ela, está. Agora, com que interesse, eu não sei, infelizmente."

"Não é a gente que gosta menos da empresa, é a empresa que gosta menos da gente".

\section{Sobre o Método da Análise Coletiva do Trabalho}

Durante todo o estudo, a participação dos trabalhadores foi grande. Cada reunião começava com uma explicação do projeto e de seus objetivos: conhecer o trabalho dos petroleiros a partir do que eles falariam sobre sua atividade. Invariavelmente, esta apresentação causava surpresa, pois na presença de pesquisadores externos, os trabalhadores acreditavam que iriam mais ouvir do que falar, isto é, exatamente o contrário do que era proposto. E do que de fato acontecia. A partir de perguntas colocadas, no início pelas pesquisadoras mas também pelos próprios colegas no decorrer do processo, ia-se descrevendo o trabalho de cada um , o trabalho do grupo todo, muitas vezes com o auxílio de desenhos, esquemas, gestos. Tudo o que tinha a ver com o trabalho real aparecia, de um modo ou de outro: explicado friamente ou avaliado calorosamente. Na realidade, a ACT oferece um espaço privilegiado para que se fale de um assunto que é poucas vezes formalizado: a atividade de trabalho de cada um.

\section{Considerações Finais}

Através de dois métodos diferentes, estudamos a atividade de trabalhadores na área do petróleo no Brasil. Com a AET, pudemos nos debruçar sobre a atividade dos operadores em uma unidade de refino. Observamos seus gestos,ouvimos suas explicações, conhecemos seus equipamentos e instrumentos, medimos as distâncias que percorriam e as vezes em que se comunicavam entre si. Analisamos documentos técnicos e organizacionais, acompanhamos e cronometramos suas rotinas de trabalho em períodos calmos $\mathrm{e}$ tumultuados, quando a tarefa que tinham era resolver problemas complicados. Em todo este processo pudemos constatar a complexidade de sua tarefa e o alto grau de capacitação e de responsabilidade que ela envolvia. Constatamos também a inadequação de métodos simplistas de estudo das tarefas para dar conta do trabalho que acontece numa unidade de refino e pudemos dar uma resposta clara 
ao problema de diminuição de efetivos, motivo da demanda que provocou nossa intervenção. Com a ACT, ao contrário, ao invés de nos aprofundarmos em uma situação específica, tivemos a oportunidade de conhecer a atividade de trabalhadores exercendo várias funções dentro da indústria do petróleo e compreender melhor o que era específico a cada uma delas e o que era comum a todo o trabalho: ser perigoso, complexo, contínuo e coletivo. Pudemos também constatar o enorme envolvimento dos trabalhadores com o seu trabalho e com os destinos da empresa.

Com o recuo, podemos tentar tirar algumas lições destes dois estudos, algumas metodológicas e outras sobre o trabalho no petróleo:

1-A análise da atividade dos trabalhadores, isto é, o que eles fazem concretamente para dar conta das exigências das tarefas em suas situações de trabalho é um potente instrumento para se conhecer a realidade do trabalho. Em geral, os estudos sobre o trabalho se detêm na análise das tarefas, isto é, nos objetivos, nos meios de trabalho, nos procedimentos e nos desempenhos exigidos, que não dão conta nem da complexidade das situações de trabalho nem da criatividade e do esforço dos trabalhadores para enfrentálas. A AET e a ACT são alguns dos possíveis métodos que se pode utilizar para melhor conhecer a atividade dos trabalhadores. Na AET, a análise é feita em uma situação de trabalho específica para se responder a uma questão específica. A atividade dos trabalhadores não é o objetivo da análise mas um meio de se melhor entender o problema e propor respostas concretas para ele, que impliquem em uma mudança na situação de trabalho. É feita por ergonomistas,ou seja, o olhar que se tem da atividade de trabalho é um olhar externo, muito embora os ergonomistas devam, para fazer um bom estudo, ouvir os trabalhadores envolvidos. Na ACT, conhecer a atividade dos trabalhadores é o objetivo final. Como são eles que melhor sabem o que fazem concretamente para responder as exigências de suas tarefas, a análise é feita a partir de suas descrições sobre a sua atividade, realizada fora do local do trabalho. O papel dos pesquisadores/ ergonomistas é apenas o de ajudar que o conhecimento que cada trabalhador tem sobre a sua atividade aflore e seja verbalizado e explicado para um grupo de pessoas interessados em conhecê-la. Tratase de trabalhar a partir de "conhecimentos adormecidos", isto é "certos conhecimentos que não são conscientes simplesmente porque o sujeito ou as pessoas em torno deles nunca se perguntaram sobre eles" (Vermesch,1991). De fato, a atividade de trabalho é muito mais vivida do que pensada. O que a ACT propõe é que ela se torne um objeto de reflexão.

2- Trabalhar com os sindicatos de trabalhadores é uma opção extremamente promissora para o estudo da atividade em situação de trabalho, por vários motivos:

a) Sendo a atividade dos trabalhadores o objeto da análise, é necessário ter acesso a eles, o que não é fácil por inúmeros 


\section{PRODUÇÃO}

motivos. Através de seus sindicatos, este acesso é muito facilitado e garante, inclusive, que o voluntariado seja respeitado.

b) O papel dos pesquisadores "é desmistificado. $O$ pesquisador não aparece como aquele que sabe dos problemas e de suas soluções, mas como alguém que está disponível para compreender uma realidade que não conhece e contribuir para seu esclarecimento, o que é um primeiro passo para que se comece a pensar em propostas de mudanças.

c) Abrem-se novos horizontes para a pesquisa acadêmica, pois vivencia-se uma infinidade de problemas concretos do mundo do trabalho, em geral desconhecidos pela comunidade científica, mas que estão a exigir a sua contribuição

d) No processo conjunto de pesquisa, o sindicato começa a se engajar mais profundamente no campo das condições de trabalho, o que representa uma perspectiva fecunda de ampliação de seus campos de atuação.

3-Apesar (ou por causa de?) da indústria do petróleo ser estratégica no desenvolvimento mundial, é muito difícil se obter dados sobre o trabalho de seus empregados ou sobre suas condições de trabalho.

Quanto ao número de trabalhadores, "os dados internacionais são notoriamente imprecisos", já dizia em 1986 a Organização Internacional do Trabalho, em um relatório sobre planificação de mão de obra na indústria do petróleo (OIT, 1986). As estatísticas mais completas eram as dos países da Comunidade Européia e em geral faltavam dados sobre a força de trabalho produtiva da China. As estimativas feitas para o ano 2000 davam um contingente de aproximadamente 3 milhões de trabalhadores empregados em todo o mundo. O mesmo estudo dizia que "nos útimos anos, a principal preocupação das refinarias ocidentais foi reduzir custos de funcionamento para se manter ativas èm uma época de enorme super capacidade. $O$ resultado foi uma notável diminuição do emprego na Europa e na América." Dados mais recentes confirmam esta tendência. No começo do decênio de 1980, se registrou na Europa Ocidental uma considerável redução da capacidade de refino e de emprego: entre 1980 e 1993, se passou de 150 refinarias com um número médio de 1000 trabalhadores cada uma a pouco mais de 100 refinarias, com um número médio de 500 empregados (OIT,1995 a) .O que aconteceu na Esso nos Estados Unidos confirma esta tendência. Durante a década de 80 , a empresa eliminou milhares de empregos e esta reestruturação teve até repercussões externas: a imprensa norte-americana sugeriu que a medida estivesse relacionada com um grande acidente ecológico acontecido em 1992 no porto de Nova York, com o vazamento de centenas de milhares de galões de petróleo (Mattera,1992).O grave acidente na refinaria francesa de La Mède, em 1992, também provocou fortes reações dos 


\section{PRODUÇÃO}

sindicatos de trabalhadores: "faz anos que alertamos as autoridades sobre os riscos de acidentes causados pela supressão de efetivos em todas estas indústrias de alto risco. A redução dos empregos, como o recurso à terceirização, se faz em detrimento da segurança." publicou o jornal Libération em 10/11/1992.

Em contraste com esta tendência, porém, muitos países produtores investiram em refinarias próprias: a capacidade primária de destilação aumentou de forma importante no Oriente Médio, no Extremo Oriente e outros países da Ásia.(OIT,1995a)

Um ponto muito valorizado pela OIT já em 1986 era a necessidade de que a planificação de mão de obra fosse feita com a participação das organizações de trabalhadores. Em geral, "os fabricantes de sistemas avançados de controle por computadores dizem que estes aumentam - a esfera de controle e portanto reduzem as exigências de pessoal. Mas uma experiência de modernização de uma refinaria, feita com a participação ativa de seus empregados, mostrou que com a introdução de novas tecnologias, embora o número de operadores de cada unidade tivesse diminuido, aumentou o número de pessoas em outros setores especializados. O nível global da mão de obra não variou. O que variou foi o balanço das qualificações".

O problema da terceirização da mão de obra, que também apareceu em nossos estudos, foi motivo de um estudo realizado pela Comissão do Petróleo (OIT,1973). Resumidamente, o estudo mostrava a extrema variedade de situações neste campo: variação do tipo de trabalho, do tipo de contratados e de regulamentações que controlavam as práticas em matéria de mão de obra terceirizada. "As preocupações dos sindicatos de trabalhadores na indústria do petróleo são semelhantes às das autoridades públicas, no sentido em que tendem a eliminar as modalidades abusivas em matéria de utilização de mão de obra de empreiteiras". Estas preocupações dos sindicatos são pertinentes. Um relatório feito em 1991 pelo instituto norte americano John Gray Institute (citado em OIT,1995b) afirmava que, em grande parte, o crescimento do trabalho terceirizado tinha correspondido a empresas sem presença sindical. "Quando os trabalhadores percebem que se suprimem postos de trabalho antes ocupados por pessoal próprio, substituidos agora por trabalhadores terceirizados, menos qualificados, pior formados, menos seguros em seu trabalho e não sindicalizados, se observa um clima de desconfiança e a exasperação nas empresas estudadas em que há uma presença sindical. $O$ desejo de evitar a sindicalização é uma das razões de uma maior utilização de trabalhos terceirizados, seja isto ou não um objetivo deliberado."

Em relação às condições de trabalho nas empresas, é difícil se formar uma idéia de conjunto. Perrow (1984), um norte americano especialista em grandes acidentes industriais, se queixava da falta 


\section{PRODUÇÃO}

de documentação sobre incêndios e explosões ocorridos em plantas químicas norte americanas: toda documentação existente só circulava entre as próprias empresas. Ele chegava mesmo a dizer que se conhecia mais sobre acidentes nucleares do que sobre acidentes em petroquímicas, porque na área nuclear havia uma agência governamental para fiscalizar este tipo de atividade, o que não acontecia na indústria química americana. Esta situação parece ter melhorado mais recentemente, principalmente no que diz respeito ao controle ambiental: uma legislação de 1986, nos Estados Unidos estabeleceu normas sobre o "direito à informação"em virtude das quais é obrigatório para as refinarias de petróleo, entre outras, divulgar informaçōes sobre as substâncias tóxicas armazenadas e as descargas anuais de substâncias químicas no meio ambiente (OIT,1995a). Na Europa, a situação é um pouco diferente. Laboratórios de ergonomia e de psicologia do trabalho têm estudado o trabalho em processos contínuos, entre eles refinarias de petróleo, e dado contribuições importantes (Daniellou et allii, 1983; Daniellou,1985; De Keyser; 1988; Davezies, 1992). Mas também aí grandes acidentes são tratados confidencialmente. No Japão, a maioria dos assuntos relacionados às condições de trabalho, saúde e segurança dos trabalhadores são confidenciais (Petrobrás-Idemitsu,1993).

Neste quadro de tantos segredos, as companhias de seguro podem ser fontes preciosas de informações. Em um levantamento feito por uma companhia de seguro norte americana em 1989, sobre os cem maiores acidentes com perdas materiais ocorridos nos útimos 30 anos em refinarias, petroquímicas, usinas de processamento de gás e terminais, apenas um aconteceu no Brasil. A maioria deles (60\%) ocorreu nos Estados Unidos. O mesmo levantamento também mostra que os acidentes estão ficando cada vez mais caros: as perdas materiais destes acidentes foram avaliadas em 5,25 bilhões de dólares. Mas talvez o mais interessante seja a análise das causas dos acidentes: apenas $10 \%$ foram decorrentes de "falhas humanas". A grande maioria foi atribuida a "causas estáticas" como a falha de equipamentos ou "dinâmicas", como a perda de um contaminante devido ao vazamento incontrolável de uma válvula. Esta análise reforça a idéia da complexidade e do perigo do trabalho e da necessária competência de seus trabalhadores.

4- Faltam, no Brasil, estudos mais sistemáticos sobre o trabalho dos petroleiros, que se debrucem sobre os principais problemas que estes trabalhadores vem enfrentando e que enfrentarão no futuro. É necessário que as experiências já vividas por outras empresas sejam conhecidas e analisadas para que os mesmos erros não sejam novamente cometidos e que os acertos sejam incentivados. Não há um modelo único para o trabalho no petróleo. Ele precisa ser forjado em cada país respeitando sua história e, se for feito junto com seus trabalhadores, o que infelizmente 


\section{PRODUÇÃO}

não vem ocorrendo por aqui, terá mais garantias de sucesso.

5- Em um brilhante artigo onde analisa algumas catástrofes industriais, Wisner (1994) faz um veemente apelo à comunidade científica internacional para que pesquise melhor os sistemas industriais complexos e perigosos, como modo de se evitar novos e drámaticos acidentes. É necessário, diz ele, que se abandone os métodos simplistas de análise de acidentes, que no máximo se restringem a registrar responsabilidades de operadores e seus dirigentes imediatos e passar para um nível mais amplo, que inclua desde o pessoal que concebe e instala os dispositivos técnicos até o dos que determinam as condições econômicas, sociais e até políticas, nos quais o dispositivo foi instalado e explorado. Fazemos nossas as palavras do professor.

\section{Notas}

1. A partir deste relatório, o Ministério Público entrou com uma ação contra a empresa exigindo a reposição de pessoal e a ganhou em primeira instância

2. Durante a elaboração deste texto, o Congresso Nacional aprovou em primeira votação a quebra do monopólio estatal do petróleo 


\section{Referências Bibliográficas}

BRASIL Constituição da República Federativa do Brasil, TítuloII, Capítulo II, Artigo 7, item XIV, 1988.

DANIELLOU, François. La modélisation ergonomique de l'activité de travail dans la conception industrielle: le cas des industries de processus continu.Tese de Doutorado CNAM, Paris, 1985 .

DANIELLOU, François.; BOEL, M.; DESSORS, Dominique; LAVILLE, Antoine.; TEIGER,Catherine; VILLATE, Robert. L'activité des opérateurs de conduite dans une salle de controle de processus automatisé. Collection Ergonomie et Neurophysiologie du Travail, n 75, CNAM, Paris, 1983.

DAVEZIES, Philipe.; JAYET, Christophe. Confiance et visibilité du travail: l'impact des transformations technologiques sur le fonctionnement collectif dans une raffinerie.Communication au XXVII Congrès d'Ergonomie de Langue Française, Lille, 1992.

DEJOURS,Christophe. A loucura do trabalho. Ensaio de psicopatologia do trabalho. Trad. de Ana Isabel Paraguay e Lucia Leal Ferreira. 5 ed. Ed CORTES/ OBORÉ, São Paulo, 1992.

DE MONTMOLLIN, Maurice. L'inteligence de la tâche. Eléments d'ergonomie cognitive. 2 edition. Berne, Francfort-s.Main, New York: Lang, 1986.
DE KEYSER, Veronique. De la contingence à la complexité: l'évolution des idées dans l'étude des processus continus. Le Travail Humain 51 1: 1 pp 11988.

DUARTE, Francisco José de Castro Moura. A Análise Ergonômica do Trabalho e a determinação de efetivos: estudo da modernização tecnológica de uma refinaria de petróleo no Brasil. Tese de Doutorado em Engenharia de Produção, COPPE-UFRJ, 1994, 148p.

FERREIRA, Leda Leal. A Análise Coletiva do Trabalho. Revista Brasileira de Saúde Ocupacional,_n 78, vol21 abril/ junho 1993, p7-19.

FERREIRA, Leda Leal e IGUTI, Aparecida Mari. O trabalho dos petroleiros: perigoso, complexo, contínuo e coletivo. FUNDACENTRO, 1994, 135p.

FERREIRA, Leda Leal; IGUTI, Aparecida Mari; JACKSON, José Marçal. Análise do trabalho dos operadores na unidade de gasolina de aviação da refinaria Presidente Bernardes de Cubatão da Petrobrás. Estudo solicitado pelo Ministério Público do Estado de São Paulo ao Setor de Ergonomia da FUNDACENTRO. São Paulo, 1991, 131p.

MATTERA, Philipe. World class business: a guide to the 100 most powerful global corporations 1 ed. A Henry Holt Reference Book, New York, 1992. 


\section{PRODUÇÃO}

ORGANIZACIÓN INTERNACIONAL DEL TRABAJO Problemas sociales de los trabajadores contratados por empresarios y subcontratistas y de los trabajadores eventuales en la industria del petroleo. Comision del Petroleo, octava reunion, Ginebra, 1973.

Planificacion y desarrollo de la mano de obra en la industria del petroleo Comision del Petroleo, decima reunion, Ginebra, 1986.

Situación reciente en el sector de las industrias químicas.Undécima reunión. Informe I. Programa de Actividades Sectoriales.Ginebra, 1995a

La incidencia en el empleo y la formación de la evolución estructural de las industria químicas.Undécima reunión. Informe II. Programa de Actividades Sectoriales, Ginebra, 1995b.

PERROW, L. Normal accidents. Basic Books, New York. 1984.

PETROBRÁS- Sistema Petrobrás, diagnóstico e perspectiva. outubro 1993.

PETROBRÁS-IDEMITSU Anais do Seminário de tecnologia em refino. Fevereiro 1993.

VERMESCH, Pierre. Les connaissances non-conscientes de l'homme au travail. Le journal des psychologues, 1991.
WISNER, Alain. A metodologia na ergonomia: ontem e hoje. in WISNER, A. A inteligência no trabalho-textos selecionados de ergonomia. Trad de Roberto Leal Ferreira. São Paulo, FUNDACENTRO, 1994.

$$
\text { O trabalhador }
$$

diante dos sistemas complexos e perigosos.in WISNER, A. A inteligência no trabalho: textos selecionados de ergonomia. Trad de Roberto Leal Ferreira, São Paulo, FUNDACENTRO, 1994.

WISNER, Alain; DANIELLOU, François; DEJOURS, Christophe. Uncertainty and anxiety in continuous process industries. in NORO, K. Occupational health in automated factory.London, Taylor and Francis, 1987.

SEM AUTOR Une explosion pulverise le coeur de la raffinerie Total. Libération, 10/11/92, Paris.

SEM AUTOR Large property damage losses in the hydrocarbon chemical process industries: a thirty year review. Loss Prevention Bulletin, june 1991, n 99 p1-30.

Artigo recebido em dez/1996, avaliado em março/1996 e aprovado para publicação em julho/1996 